Orirginal Contribution

\title{
BODY AWARENESS AND RESPONSES TO EXPERIMENTALLY INDUCED PAIN
}

\author{
M. Minev*, M. Petkova, B. Petrova, R. Strebkova \\ Department of Medical Psychology and Foreign Languages, Medical Faculty, \\ Trakia University, Stara Zagora, Bulgaria
}

\begin{abstract}
PURPOSE. The aim of this study is to discuss personal and demographic factors that influence the relationship between physical activity and awareness of one's own body, as well as the pain response (threshold and tolerance of pain), situational anxiety and personality. In the study 38 healthy individualvolunteers, students in Trakia University - Stara Zagora were selected. All participants were divided into two groups: actively involved in individual or team sport $(n=19)$ and healthy normaly active subjects (non-athletes, $\mathrm{n}=19$ ). The age of the study participants ranged between 18 and 39 years, while the gender breakdown was as follows: men - 22 women - 16. Methods: Psychological Questionnaires: Body Awareness Questionnaire that asks subjects to rate, on a 4 point scale, the degree to which they were currently experiencing symptoms of sympathetic arousal, State Trait Anger Scale, and State Trait Anxiety Scale. Objective methods (cold pressure test) are used only to determine the pain sensation and pain tolerance thresholds. The results of investigation support significant differences between athletes and non-athletes in pain thershold, body awareness and anxiety. The study conclusions discuss body awareness as an increasing factor for pain resistance in athletes and as an integral part of the learning process among them.
\end{abstract}

Key words: Body awareness, experimental pain, cold pressor test, pain tolerance, pain threshold

\section{INTRODUCTION}

During last years body awareness is outlined as an object of scientific research in a wide spectrum of health topics. Definition "body awareness" includes focus of attention and internal senses of body awareness (1). This is the notion of a person about the condition of their body and about their personal capacity, too. It is formed through internal body senses awareness and includes the notion of different physique senses (for example, heart activity sense, position of limbs, as some complex syndrome like pain, relaxation sense and somatic features of emotions) (2). It's supposed (3) that body awareness is a product of interacted dynamic processes with cognitive evaluations and subconscious influences and is formed by individual's frame of mind, convictions and experience in social and cultural context. Body awareness is considered to be a product of dynamic processes

\footnotetext{
*Correspondence to: Milen Minev, Department of Medical Psychology and Foreign Languages, Medical Faculty, Trakia University, 11 Armejska Str., Stara Zagora, 6000 Bulgaria.Tel.: +359 886622101; E-mail:m_minev@abv.bg
}

permanently interacted in between, connected to: a) afferent, efferent, b) cognitive evaluations and subconscious influences and c) thoughts, beliefs and experience of the subject in social and cultural environment (1).

The term is conventionally used in researches of anxiety and panic disorder to describe the cognitive attitude, characterized with excessive focus of patient on physique symptoms, increase ("somatosensory increase"), experience, and beliefs for catastrophic consequences (4).

This conceptualization for body awareness supposes potential exhausting body sense which is widely used as a marker of hypochondria, anxiety and somatization (5), all of them strongly connected with unfavorable clinic results, as trajectory of pain (6).

Respectively, dominated view in medical and behavior science consider increased awareness of somatic information as potentially anxious and inadaptable. There is a serious anxiety among clinicians that efforts for increasing body information are focused on body 
symptoms that can cause mania or sense of bodily functions without any reason (7).

Therefore, when this understanding for body information is referred to pain, it is possible to wait its positive influence by dispelling attention through focus directed away from pain senses - towards mental activities, as mathematical problems, for instance. In fact, experimental pain researches or other models of sharp pain demonstrate such results (8).

Nervous system through its vegetative structures takes part in so called physiological response to pain stimulus, included for instance blood pressure and heart frequency (9). From neurophysiological point of view, this definition of core-construct of body awareness, even though it's closely defined, is referred to first of all proprioception and interception. Interception is the perception of senses from inner part of the body and includes perceptions of physical senses, connected with inner organs function, as heard rhythm, breathing and vegetative nervous system activity, connected with emotions (10).

Information for physical senses, connected with emotions is a key element of sense of oneself (11). A considerable amount of researches are available for the last decades that prove correspondence between fair, anxiety and pain sense, including tolerance and pain threshold ( $1-12)$. Simultaneously, there is a small amount of experiments to find complex influence of psychological factors influenced on these characteristics of pain. They can be personal features that have high coefficient of correlation with anxiety (13), and stable models of behavior, too (14). These models are well established often among sportsmen during training and/or competitions.

The aim of present research is to analyze personal and demographic factors, influenced the connection between physical activity and body awareness, pain reaction (threshold and tolerance of pain), and anxiety - situated and personal.

\section{METHODS}

Subjects. After thorough analyze of medical documentation and preliminary interview with a doctor, 38 healthy people - volunteers, students from Thracian University - Stara Zagora, joined in the research, divided in two groups: gr.1. Active training individual and collective sports $(n=19)$ and gr.2. Healthy, not active training $(n=19)$. The age of participants in the research vary between 18 and 39 years old, distribution by gender as follows: men -
22 , women -16 . In all the study, we strongly observed the rules of the the local ethical committee at Trakia University and the principles of the Declaration of Helsinki (1964). An informed consent was obtained from all participants before initiation of the experimental procedures. They were informed that they could discontinue the study whenever they wanted and without giving any reason for their decision.

\section{Experimental procedure.}

Questionnaires. Body Awareness Questionnaire (BAQ) (15). The questionnaire is with proved reliability and validity. It is intended for estimation of sympathetic arousal. The questionnaire represents a scale of 4 points for estimation of sympathetic arousal degree at the moment of research. Higher marks by this method are indicators for higher body awareness, lower - for lower degree. Spielberger Anxiety Test - Adapted for Bulgarian conditions by D. Shtetinski and I. Paspalanov (16). The test consists 2 subscales: Scale for situation anxiety (STAI - Form Y-1) - consists of 20 statements, that evaluate how the analyzed person feels "at the present moment", Scale for personal anxiety (STAI form Y-2) consists of 20 statements, that evaluate how the analyzed person feel "in general" Both groups analyzed people fill in questionnaires, after that they are undergone cold pressing test. For the group of regularly sporting people this happens in the end of work/school day; for the group of athletes the research is in the end of school day, but before consecutive training.

Cold pressor test. Methods of experimental cold inducted pain are widely used for test of stressing changed behavioral models among people and animals (17-18). Cold pressing test is one of the most applying methods for experimental pain research (19). It allows registering of physiological act of pain as changes in heart frequency and blood pressure, through that it is possible to indicate sympathetic or parasympathetic branch of vegetative nervous system (20). The common cold pressing effect during the research is rising of systolic and diastolic blood pressure with around 10-20 $\mathrm{mm} \mathrm{Hg}$ and tendency of arising of heart frequency (21). Despite availability of different explanations about cold pressing effect, it is at hand unanimity of vegetative nervous system participation (22) that proves the role of stress, constitutional characteristics, gender, mental status and inherited factors during cold pressing response $(23,24)$. During CPT dominated hand of the 
participant was immersed till wrist in freezing cold water $\left(4 \pm 0.5^{\circ} \mathrm{C}\right)$. Before immersing of the hand experimenter describes the procedures the participant and instructs to keep the hand in water as long as possible. The participants have to give sign for the first pain (threshold of pain) and when the pain becomes unbearable to withdraw their hand from cold water (tolerance of pain). The blood pressure and heart frequency of participants were measured before, during and immediately after concluding the CPT. In lack of unbearable pain (high tolerance) CP test was stopped at $5^{\text {th }}$ minute.

Statistical analysis. All statistical analyses were performed using SPSS v. 20, (SPSS, Chicago, IL). Analysis of variance (ANOVA) was used to determine the significance of differences between groups. To analyze differences in pain measures within groups paired $\mathrm{t}$ - tests were used. Differences were considered significant when $p<0.05$. Empiricist data are processed thanks to statistic program SPSS. Descriptive statistics and correlation analysis are applied.

\section{RESULTS AND DISCUSSION}

The results of research show simultaneously higher tolerance to experimental induced pain and higher reading of body awareness among athletes. Confirms the hypothesis that stress of forthcoming training in connection with higher body awareness raises stability towards pain and/or specifically changes the perception of it. This is in accordance with results from former researches, in which statistically differences between two groups are available (15) (Table 1).

Table 1. Comparison of groups of athletes and athletes body awareness ( $t$ test Student)

\begin{tabular}{|l|l|l|l|l|}
\hline \multirow{2}{*}{$\begin{array}{l}\text { body } \\
\text { awareness }\end{array}$} & sport & $\begin{array}{l}\text { Standard } \\
\text { deviation }\end{array}$ & $\begin{array}{l}\text { Ratio Styudant- } \\
\text { t-test }\end{array}$ & $\begin{array}{l}\text { Level of } \\
\text { significance }\end{array}$ \\
\cline { 2 - 5 } & sportsmen & 0,61 & 1,87 & $p<0,05$ \\
\hline
\end{tabular}

Our results correspond to other researches, proved that tested participants, who are in stress (pain+sport) have higher awareness levels and changes in pain sense (1) (Figure 1).

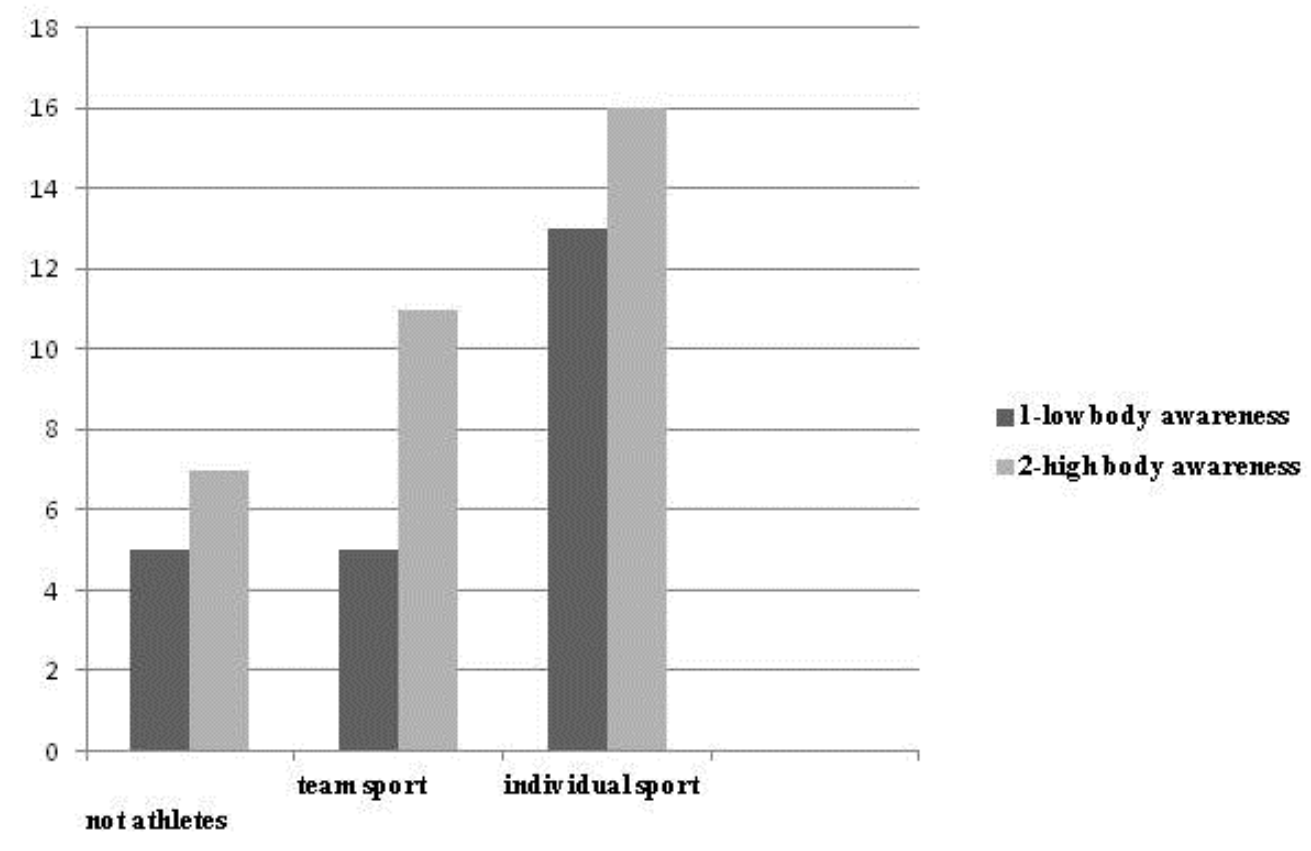

Figure 1. Significance of the difference in the values of body awareness factors sports

It was established availability of statistically significant difference between body awareness and pain threshold; those that have high level of body awareness, have higher threshold ( $\mathrm{t}=1$, $61 ; \mathrm{p}<0.05)$. It was not established contrast of body awareness readings and pain tolerance 
$(\mathrm{t}=0,44 ; \mathrm{p}<0.05)$. The difference between readings is small, statistically insignificant. In experimentally induced pain in bigger part of researches is shown that as among animals (25) so among people, the females are comparatively more sensitive towards such kind of simulation in comparison with male (18-23-26). In conformation of this is received by us result - females have higher body awareness than males (Table 2).

Table 2. Comparison of the values of body awareness by gender ( $t$ Student criterion)

\begin{tabular}{|l|l|l|l|l|}
\hline \multirow{3}{*}{ body awareness } & sex & Standard deviation & $\begin{array}{l}\text { Ratio Styudant- } \\
\text { t-test }\end{array}$ & $\begin{array}{l}\text { Level of } \\
\text { significance }\end{array}$ \\
\cline { 2 - 6 } & men & 0,44 & 1,69 & $p<0,05$ \\
& women & & 1,69 & $p$ \\
\hline
\end{tabular}

It was established availability of statistically significant difference between anxiety level and body awareness readings. Tested sportsmen, who have higher level of situated anxiety, have higher readings of body awareness $(t=-3,50 ; p<0.05)$. There is a significant difference between personal anxiety level and body awareness readings, too. The tested sportsmen who have higher level of personal anxiety, have higher body awareness level $(\mathrm{t}=-2,58 ; \mathrm{p}<0.05)$. Athletes in comparison with not doing sports have higher level of body awareness and higher threshold pain. It wasn't established statistically significant difference between pain tolerance and body awareness among sportsmen. It was established availability of statistics significance between situated anxiety and body awareness; those among tested sportsmen, who have higher level of situated anxiety, have higher readings in body awareness. Such significance we discover between personal anxiety level and body awareness readings; those of tested sportsmen who have higher level of personal anxiety, have higher readings of body awareness. The result can be analyzed so: sportsmen under stress (pain+sport) have higher awareness levels, and their anxiety level raise. Analysis of results comes to the following summaries:

1. Sportsmen have higher readings of body awareness to not doing sports.

2. Active sportsmen have higher threshold pain in comparison to those who do not do sports.

3. Established by us higher body awareness among females in comparison to males points that they are more sensitive to experimental induced pain in comparison to males.

4. Those of sportsmen, who have higher situated and personal anxiety levels, have higher body awareness readings.

\section{CONCLUSIONS}

In the course of accomplished by us research of body awareness and reactions towards experimentally induced pain among healthy sportsmen and not active doing sports people were established:

1. Pain and its neuro-vegetative effects influence on cardiovascular system and sensitivity of nervous system is accepted as invariable part of training process among sportsmen.

2. Higher body information as whole raises pain stability and changes perception towards it.

\section{ACKNOWLEDGMENTS}

This study was supported by Grant 18/2015 from the Medical Faculty, Trakia University, Stara Zagora, Bulgaria.

\section{REFERENCES}

1. Bekker, M., Croon, M., van Balkom, E., Vermee, J., Predicting individual differences in autonomy-connectedness: the role of body awareness, alexithymia, and assertiveness. J Clin Psychol, 64: 747-765, 2008.

2. Aronson, K., Barrett, L., Quigley, K., Emotional reactivity and the over report of somatic symptoms: somatic sensitivity or negative reporting style? J Psychosom Res, 60: 521-530, 2006.

3. Eccleston, C., Crombez, G., Aldrich, S., Stannard, C., Attention and somatic awareness in chronic pain. Pain, 72: 209215, 1997.

4. Steptoe, A., Noll, A., The perception of bodily sensations, with special reference to hypochondriasis. Behav Res Ther, 35: 901910, 1997.

5. Cioffi, D., Beyond attentional strategies: cognitive-perceptual model of somatic interpretation. Psychol Bull, 109: 25-41, 1991. 
6. Pincus, T., Burton, A., Vogel, S., Field, A., A systematic review of psychological factors as predictors of chronicity/disability in prospective cohorts of low back pain. Spine, 27: E 109-120, 2002.

7. Kirmayer, L., Looper, K., Abnormal illness behavior: physiological, psychological and social dimensions of coping with distress. Curr Opin Psychiatry, 19: 54-60, 2006.

8. Johnson, M., How does distraction work in the management of pain? Curr Pain Headache Rep, 9: 90-95, 2005.

9. Bogaerts, K., Millen, A., Li, W., De Peuter, S., Van Diest, I., et al., High symptom reporters are less introspectively accurate in a symptom-related context. J Psychosom Res, 65: 417-424, 2008.

10.Cameron, O., Interoception: The inside story - a model for psychosomatic processes. Psychosom Med, 63: 697-710, 2001.

11.Bechara, A., Naqvi, N., Listening to your heart: interoceptive awareness as a gateway to feeling. Nat Neurosci, 7: 102-103, 2004.

12.Nikolov, V., Petkova, M., Hristakieva, E., Manchev, I., Stoyanov, B., Effect of anxiety on the perception of chronic pain, Trakia Journal of Science, Vol. 6, Number 2, Suppl. 2, 39-43, 2008.

13.Petrova, B., Mineva, K., Nikolov, V., Petkova, M., The effect of anger on experimentally induced pain. Trakia Journal of Sciences, Vol. 12, Suppl.1, 385389, 2014.

14.Petkova, M., Nikolov, V., Mineva, K., Petrova, B., Psychological factors of correlation between pain tolerance, pain threshold and obesity. Trakia Journal of Sciences, Vol. 12, Suppl.1, 381-384, 2014.

15.Stephanieq, A., Mallory, M., Simon, A., The Body Awareness Questionnaire: Reliability and Validity. Journal of Perssonality Assessment, 53(4), 802-815. 1989.

16.Paspalanov, I., Stytinski, D., Methodical tool for working with the Bulgarian form of the questionnaire for assessing the anxiety of C. Spielberger. Sofia: BAS Institute of Psychology, 1989.
17.Dzhambazova, E., Ivanova, F., Lambadjieva, N., Nikolov, V.. Effects of cold stress on spontaneous behavior of rats. Trakia Journal of Sciences, Vol. 10, Suppl.1, 203-206, 2012.

18.Nikolov, V., Petkova ,M., Petrova, B., Mineva, K., Pain perception to the cold pressor test in reproductive-age women: Relation to menstrual phase and comparison with men. Trakia Journal of Sciences, Vol. 12, Suppl.1, 376-380, 2014.

19.Nikolov, V., Petkova, M., Petrova, B., Mineva, K. Student's Pressure Test as a Model for Experimental Pain Study, Collection of Scientific Reports of the National Conference "Psychology in Medicine" - 7-8 February, 81-89, 2014.

20.Flor, H., Denke, C., Schaefer, M., Grusser, S., Effect of sensory discrimination training on cortical reorganisation and phantom limb pain. Lancet ,357: 1763-1764, 2001.

21.Feipel, V., Parent, C., Dugailly, P., Brassinne, E., Salvia, P., et al., Development of kinematics tests for the evaluation of lumbar proprioception and equilibration. Clin Biomech (Bristol, Avon), 18: 612-618, 2003.

22.Laskowski, E., Proprioception. Scient Princ Sports Rehab, 11: 323-340, 2000.

23.Mailloux, J., Brener, J., Somatosensory amplification and its relationship to heartbeat detection ability. Psychosom Med ,64: 353-357, 2002.

24.Bruehl, S., Burns, J., Chung, O., Chont, M., Pain-related effects of trait anger expression: Neural substrates and the role of endogenous opioid mechanisms. Neuroscience\& Biobehavioral Reviews, 33(3):475-491, 2009.

25.Nikolov, V., Petkova, M., Effects of estrogen on pain induced behavioral responses in ovariectomized rats. Trakia Journal of Sciences, Vol. 10, Suppl.1, 175177, 2012.

26.Nikolov, V., Petkova, M., Pain sensitivity among women with low estrogen levels. Procedia Social and Behavioral Sciences, Vol. 5, 289-293, 2010. 